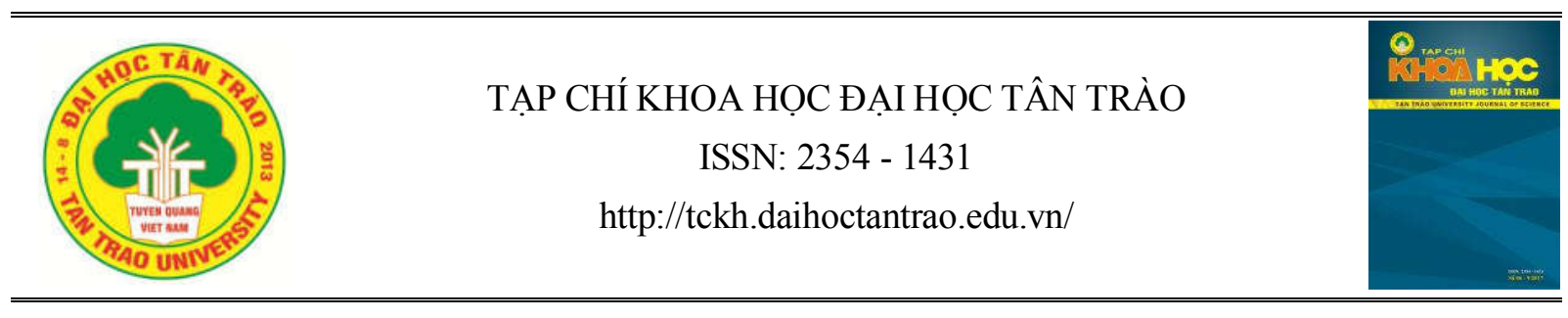

\title{
Tiềm năng phát triển du lịch Trekking tại vườn quốc gia Xuân Sơn, tỉnh Phú Thọ
}

Đỗ Tuyết Ngân $n^{a^{*}}$

${ }^{a}$ Truờng Đại học Khoa họ, Đại học Thái Nguyên

*Email:dtngandl52@gmail.com

\section{Thông tin bài viết}

Ngày nhận bài:

06/4/2019

Ngày duyệt đăng:

$10 / 6 / 2019$

\section{Tù̀ khóa:}

Du lịch, du lịch trekking;

lợ thế phát triển; vuoòn quốc gia Xuân Son; tỉnh Phú Tho

\section{Tóm tắt}

Du lịch Trekking là loại hình du lịch chuyên biệt mới xuất hiện ở Việt Nam vào thập niên 1990, khi đất nước vừa mở cửa. Đến nay, một số khu vực có lợi thế về khai thác hoạt động du lịch trekking đã tận dụng tối đa lợi thế đó để phát triển, trong đó phải kể đến Sapa và Lâm Đồng, nơi mà loại hình du lịch trekking rất phổ biết đối với du khách quốc tế và các nhà nghiên cứu. Với sự hấp dẫn về tài nguyên thiên nhiên, nhất là sự đa dạng về địa hình và phong tục độc đáo của các dân tộc thiểu số, vườn quốc gia $(\mathrm{VQG})$ Xuân Sơn là một điểm đến đang được chú ý cho loại hình trekking bởi có những đặc trưng cơ bản cho điều kiện tài nguyên phục vụ cho loại hình du lịch này. Do đó, bài nghiên cứu nhằm phân tích một số tiềm năng để khai thác loại hình du lịch trekking một cách hiệu quả tại VQG Xuân Sơn.

\section{Mở đầu}

Theo kết quả điều tra của Tổng cục Du lịch năm 2017, tỷ lệ khách du lịch quốc tế đến Việt Nam từ lần thứ 2 trở lên đạt 40,4\%, trong khi đó tỉ lệ này ở Thái Lan là $70 \%$ và Singapore là $60 \%$. Như vậy, nếu so sánh với các nước trong khu vực có cùng điều kiện và tiềm năng thì tỉ lệ này của Việt Nam còn thấp. Có rất nhiều nguyên nhân khiến du khách quốc tế không muốn quay trở lại Việt Nam trong đó không thể không kể đến nguyên nhân là do sản phẩm du lịch còn nghèo nàn, chưa đa dạng. Trong thời gian tới, để du lịch thực sự trở thành ngành kinh tế mũi nhọn như mục tiêu đề ra trong “Chiến luợc phát triển du lịch Việt Nam đến năm 2020, tầm nhìn 2030” thì cần phải đa dạng hóa sản phẩm, đặc biệt làm phong phú hơn nữa các sản phẩm của du lịch.

Du lịch trekking là hoạt động du lịch chuyên biệt theo hướng đòi hỏi sự vận động và trải nghiệm cao. Loại hình này đang được nhóm khách thanh niên quan tâm đặc biệt. Tuy nhiên, nghiên cứu lọa hình du lịch này ở nước ta còn thiếu và chưa đáp ứng được nhu cầu phát triển kinh tế - xã hội. Việc khai thác các sản phẩm du lịch trekking đang mang tính tự phát, chạy theo lợi nhuận và thiếu trách nhiệm với tài nguyên môi trường cũng như cộng đồng địa phương. Để giải quyết vấn đề này, cần có thêm những nghiên cứu chuyên sâu tại các khu vực đặc thù phù hợp diễn ra hoạt động du lịch trekking như tại các khu bảo tồn thiên nhiên hay các vườn quốc gia.

Được biết đến là một khu vực còn nguyên sơ, tài nguyên tự nhiên đa dạng cũng như sự đa dạng của các phong tục tập quán độc đáo của đồng bào dân tộc thiểu số, VQG Xuân Sơn đang có tiềm năng lớn để thu hút khách du lịch. Do đó, việc đòi hỏi yếu tố "mới" và "lạ" tại các điểm đến du lịch mới nhiều tiềm năng như VQG Xuân Sơn là vô cùng cần thiết để thay đổi những điểm đến truyền thống đã quá quen thuộc với khách du lịch. Để tạo ra tính mới và lạ cho các điểm đến, việc khai thác các loại hình du lịch mới là việc cần thiết và trekking là một loại hình như vậy.

\section{Phương pháp nghiên cứu}

Phương pháp thu thập tài liệu: tác giả đã tìm hiểu các nghiên cứu về lý luận và thực tiễn, tập hợp tài liệu và phân loại thông tin liên quan đến du lịch trekking. Các thông tin chủ yếu thu thập từ sách, báo, internet, và đặc biệt là các công trình nghiên cứu đã có từ trước (giáo trình, luận văn, nghiên cứu khoa học, các báo cáo, 
v.v.) để làm nguồn tư liệu. Tài liệu mà tác giả sưu tập được bao gồm cả tài liệu tiếng Anh và tiếng Việt.

Phương pháp điền dã: tác giả đã tiến hành khảo sát thực địa tại VQG Xuân Sơn vào vào khoàng thời gian phù hợp diễn ra các hoạt động trekking (mùa khô tháng 9,10 ), quan sát hoạt động du lịch nói chung và treking nói riêng tại 2 tuyến (tuyến Núi Ten - Thác Ngọc - Thác Chín Tầng. và tuyến suối Vàng, thác Tình Yêu), tiến hành kiểm kê số lượng các cơ sở cung cấp dịch vụ lưu trú homestay tại đây. Qua khảo sát thực tế đã thấy được hiện trạng phương thức tổ chức du lịch trekking của VQG Xuân Sơn, của các công ty du lịch, cùng với các phương pháp phỏng vấn, quan sát, thảo luận, v.v. đã có kết luận về hiện trang khai thác du lịch tại đây. Kết quả khảo sát này được nêu cụ thể ở phần nội dung.

\section{Nội dung}

\subsection{Khái quát về du lịch trekking}

\section{Nguồn gốc}

Từ Trek xuất phát từ tiếng Nam Phi, đó là một từ của người Boer (người Phi gốc Hà Lan) có nghĩa là một chuyến đi theo xe bò. Sau này khi được sử dụng rộng rãi nó chuyển nghĩa rộng là một chuyến đi nào đó dài và gian khổ. Tiếp đó từ Trek dùng để diễn tả các chuyến đi bộ đường dài (hiking) tại Nepal; đây có thể coi là không gian đầu tiên của hoạt động $\mathrm{Du}$ lịch Trekking được gọi tên từ nửa sau thế kỉ XX [2].

\section{Một số quan niệm về trekking}

Trekking được theo nghĩa đơn giản là "đi xuyen rù̀ng và leo lên nhũng ngọn núi hoang so; đây là một hình thức rèn luyện cả thể lực lẫn ý chí rất hiệu quă". [3]

Còn theo David Noland: "Trek" là một chuyến đi bộ đường dài, nhiều ngày tù̀ một điểm $A$ đến một điểm $B$ (hay quay lại A) mà trong suốt chuyến đi đó nguò̀ đi bộ không phải mang hành lý nặng nề mà cũng không phải chuẩn bị nấu ăn". [2]

Có một số khác biệt với David Noland, Robert Strauss lại cho rằng "trek là các chuoong trình du lịch dài ngày đi vào các vùng xa xôi hẻo lánh mà các phuoong tiện giao thông khó tiếp cận, thông qua phuoong thức tổ chức đi bộ để khách du lịch tách biệt với thế giới văn minh, tìm hiểu tụ nhiên ở nhũng noi vìng sâu và vùng cao". [4]

Như vậy, có nhiều quan điểm và khái niệm vể trekking. Tổng hợp các quan điểm trên, tác giả cho rằng trekking là loại hình du lịch:
+ Được tiến hành bằng phương thức đi bộ, kéo dài một hay nhiều ngày không đơn thuần là một chuyến dã ngoại ngoài trời, đi bộ trên núi hay một chuyến leo trèo. Du khách tham gia các tour trek thực hiện chuyến đi của mình bằng hình thức đi bộ dường dài, có thể kéo dài một hay nhiều ngày. Trên đường đi có sự tìm hiểu, khám phá thiên nhiên và văn hóa bản địa để thấy được những nét đẹp và hấp dẫn của địa phương. Mặt khác, hành trình trek cũng gặp những sự vất vả và nguy hiểm đáng kể đòi hỏi thể hiện ý chí kiên cường và dẻo dai của con người.

+ Chủ yếu thực hiện ở những vùng núi có địa hình đồi núi và cao nguyên, những nơi hoang sơ, hẻo lánh. Điểm đến là các vùng thiên nhiên hoang sơ: chủ yếu là đồi núi và cao nguyên Các địa điểm được chọn thường là những khu vực núi rừng hoặc bản làng cách xa đồng bằng và thành phố, giao thông bất tiện, không có đường cho ô tô, xe máy. Các khu vực đồi núi và cao nguyên thu hút khách trekking hơn cả do sự đa dạng về địa hình, đa dạng về tài nguyên và sự độc đáo của văn hóa bản địa.

+ Thỏa mãn nhu cầu của du khách hòa mình vào thiên nhiên và cuộc sống con người ở điểm đến, rèn luyện và thể hiện bản thân, thử thách qua khả năng thích nghi và chịu đựng của con người về tâm- sinh lý.

\section{Các thành tố và cấp độ}

Các thành tố cơ bản của du lịch trekking gồm có: Độ dài chuyến đi, thời gian trek, khoảng cách đi bộ, độ cao tối đa, thách thức về thể lực.

Các cấp độ: chia thành 5 cấp độ với mức độ khó dần:

Cấp độ 1: Dành cho đối tượng là những khách du lịch đi bộ khỏe mạnh và có tinh thần tích cực không cần đến hoặc cần rất ít sự chuẩn bị cho chuyến trek

Trek cấp độ 2, 3 hay 4 chiếm đại đa số trong số những tour trek tiêu biểu trên thế giới cũng như tại Việt Nam. Vì sự phối hợp giữa các thành tố bản thân đã rất khác nhau, tùy thuộc vào các yếu tố khác đến chuyến trek như thời tiết, v.v. nên khó phân định rõ ràng giữa các cấp độ này. Tuy nhiên, trek cấp độ 3 đòi hỏi đi bộ một ngày từ 6 đến 7 giờ, sự thay đổi độ cao cách biệt từ $600 \mathrm{~m}-900 \mathrm{~m}$, cách biệt so với mực nolớc biển từ $3000 \mathrm{~m}-4500 \mathrm{~m}$.

Trek cấp độ 5 đòi hỏi một ngày đi bộ tối thiểu $10 \mathrm{~h}$, độ cao chênh lệch tối thiểu $1220 \mathrm{~m} /$ ngày, và độ cao đỉnh đạt đolọc là trên $5135 \mathrm{~m}$. Những chuyến trek nhơ vậy đòi hỏi những du khách thực sự khỏe mạnh và phải được tham gia vào một khóa huấn luyện thể lực và ý chí trước khi tham gia. [5] 
Việc phân định 5 cấp độ này đồng thời phản ánh tổng hợp các thành tố độ cao tối đa, địa hình, khoảng cách đi bộ mỗi ngày. Hiện chưa có sự phân định rõ ràng bằng một bảng tiêu chí chuẩn vì sự phối hợp giữa các thành tố của bản thân đã rất khác nhau, tùy thuộc vào các yếu tố khác nữa như: điều kiện thời tiết, các tai biến tự nhiên.

\section{Xu hướng phát triển ở Việt Nam}

Trong những năm 90, Việt Nam mới chỉ được coi như một điểm đến trong lộ trình của du khách quốc tế. Sau những chuyến thăm đó một số địa điểm miền núi, cao nguyên ở Việt Nam phù hợp với hoạt động du lịch trekking dần dần được du khách quốc tế biết đến như Sapa, Lai Châu, Điện Biên, Đà Lạt phần lớn là những nơi có truyền thống du lịch nghỉ dưỡng. Những chuyến đi trek đầu tiên được lồng ghép trong các tour mang tính khảo sát, nghiên cứu được tiến hành ở vùng núi Tây Bắc, tại một địa danh đã khá nổi tiếng từ thời Pháp thuộc: Sapa [1]. Trong khoảng hơn 10 năm qua, Việt Nam đã được một số hãng lữ hành chuyên kinh doanh du lịch trekking quốc tế chú ý, khảo sát, quảng cáo như một điểm đến chính thức và thực sự hấp dẫn. Các VQG của Việt Nam trở thành địa bàn khá phổ biến của khách du lịch trekking. Ở miền núi phía Bắc, Khu bảo tồn thiên nhiên Pù Luông (Thanh Hóa) và VQG Hoàng Liên (Lào Cai) là hai điểm đến được nhiều du khách nước ngoài thám hiểm nhất do chính sách mở nhằm phát triển Du lịch của chính quyền địa phương.

\subsection{Tiềm năng khai thác du lịch trekking tại VQG Xuân Sơn}

- Tiềm năng du lịch tụ̣ nhiên: VQG Xuân Sơn có tiềm năng to lớn cho phát triển du lịch nói chung và du lịch trekking nói riêng. VQG Xuân Sơn có hệ sinh thái đa dạng với 4 kiểu thảm rừng nguyên sinh độc đáo, kết hợp nhiều loại cảnh quan hấp dẫn như núi rừng, đồng ruộng, hang động, hồ nước, thác nước, sông suối. Do nằm ở điểm cuối cùng của dãy núi cao và dài nhất Việt Nam - Hoàng Liên Sơn nên thiên nhiên đã ưu ái, kiến tạo sự đa dạng về cảnh quan tự nhiên. Với tổng diện tích 15.048 ha và vùng đệm 18.639 ha, trong đó, khu bảo vệ nghiêm ngặt 9.099 ha, Xuân Sơn là VQG duy nhất trong cả nước có rừng nguyên sinh trên núi đá vôi với 2.432 ha. Theo thống kê, tại đây hiện có 726 loài thực vật bậc cao, hệ thực vật có các loài như re, dẻ, sồi và mộc lan chiếm ưu thế. Ngoài ra, còn có các loài thực vật quý tiêu biểu cho khu vực Tây Bắc như táu muối, táu lá duối, sao mặt quỷ và chò chỉ, chò vảy, nghiến, dồi, vầu đắng, kim giao... Trong đó, rừng chò chỉ được xem là đẹp và giàu trữ lượng nhất miền Bắc hiện nay. Về động vật, tại đây hiện có 365 loài động vật, trong đó có 46 loài ghi trong sách đỏ Việt Nam và 18 loài ghi trong sách đỏ thế giới. Bao gồm các loài đặc trưng cho hệ động vật vùng Tây Bắc như voọc xám, vượn chó, cày bạc má, sóc bụng đỏ đuôi trắng, gấu, báo, sơn dương... Đáng chú ý, theo thống kê ở tại VQG Xuân Sơn hiện có đàn Sơn Dương tự nhiên nhiều nhất cả nước. Về các loài chim thì đây là nơi cư ngụ và sinh sống của các loài gà lôi, gà tiền, đại bàng đất. Ngoài sức hấp dẫn của hệ động, thực vật phong phú, VQG Xuân Sơn có nhiều cảnh quan thiên nhiên kỳ thú. Nằm trong quần thể VQG Xuân Sơn có 3 đỉnh núi cao trên 1.000 $\mathrm{m}$ là núi Voi, núi Ten và núi Cẩn với hàng trăm hang động. Đây là những ngọn núi được đánh giá có độ cao nhất tỉnh Phú Thọ. Do là rừng nguyên sinh nên VQG Xuân Sơn cũng là nơi khởi nguồn cho nhiều sông suối như suối Lấp, suối Thang và nhiều thác nước có độ cao trên $50 \mathrm{~m}$ như thác Chín Tầng, Thác Ngọc hay thác Lưng Trời [6]. Như vậy, sự đa dạng phong phú của tài nguyên du lịch thiên nhiên chính là yếu tố không thể thiếu để khai thác loại hình du lich trekking tại VQG Xuân Sơn.

- Tiềm năng du lịch nhân văn: Trong vùng lõi vườn quốc gia Xuân Sơn hiện có hai cộng đồng người dân tộc đang sinh sống là dân tộc Dao và Mường. Cộng đồng các dân tộc nơi đây hiện vẫn giữ được bản sắc văn hoá dân tộc của mình từ trang phục, lễ hội đến các hoạt động đời sống sinh hoạt hàng ngày như đan lát đồ dùng thủ công, dệt thổ cẩm, thêu, lễ cấp sắc, múa đâm đuống, múa xòe, uống rượu hoẵng, cơm lam, v.v. Cùng với sự phong phú của sản vật, các món ăn ẩm thực tại đây như gà nhiều cựa, xôi ngũ sắc, thịt chua, rau sắng, cá suối, v.v. vùng lõi vườn quốc gia Xuân Sơn đã và đang được xây dựng thành điểm du lịch cộng đồng kiểu mẫu hấp dẫn, thu hút du khách.

- Cơ sở hạ tầng và dịch vụ cung úng: Thời gian thuận lợi cho tổ chức các hoạt động du lịch của VQG Xuân Sơn được đánh giá là khá dài (198 ngày/năm) với sức chứa du lịch lên đến trên 1000 người/ngày bởi các điểm tập kết là xóm Dù, xóm Lạng, xóm Lấp hoàn toàn đáp ứng được sức chứa của các điểm du lịch trong VQG. Ngoài ra, đường đi từ khu hành chính (trung tâm đón khách ban đầu) đến các trung tâm đón khách này cũng đáp ứng được mật độ đi lại hai chiều đi và về từ các điểm tham quan theo sức chứa. 
Bảng 3.1 Số lương nhà dân có thể cung cấp dịch vu homestay và nhà nghỉ trọ tại các xóm tại xã Xuân Sơn

\begin{tabular}{|l|r|}
\hline \multicolumn{1}{|c|}{ Xóm } & \multicolumn{1}{c|}{ Số lượng (nhà) } \\
\hline Xóm Dù & 6 \\
\hline Xóm Lấp & 4 \\
\hline Xóm Cỏi & 5 \\
\hline Tổng & $\mathbf{1 5}$ \\
\hline
\end{tabular}

(Nguồn: Số liệu tác giả khảo sát, 2018)

Hiện tại đã có 15 cơ sở cung cấp dịch vụ lưu trú homestay cho du khách du lịch. Các cơ sở lưu trú này được các hộ kinh doanh tự đầu tư vốn xây dựng nên mang tính chất bộc phát, nhỏ lẻ. Các vật liệu xây dựng gần gũi với thiên nhiên (nhà sàn, ao, vườn, kênh nước, v.v.) nhưng lại chưa có một quy chuẩn chung. Các vấn đề về vệ sinh và đặc biệt mạng lưới thông tin liên lạc (điện, mạng internet) còn hạn chế. Ngoài ra, cộng đồng địa phương chưa biết cách cung cấp các dịch vụ bổ sung khác như khuân vác, vận chuyển, lưu trú, ăn uống, v.v. cửa hàng lưu niệm và hoạt động du lịch hầu như không có. Đối với cộng đồng địa phương, du lịch còn khá biệt lập chưa có những tác động đáng kể (cả tích cực và tiêu cực) đến kinh tế, văn hóa, xã hội địa phương. Ngoài ra VQG Xuân Sơn vẫn chưa có Trung tâm Giáo dục Môi trường và Dịch vụ môi trường rừng nên khách du lịch chưa có thông tin hướng dẫn tham quan cụ thể. Việc thu thập thông tin về khách cũng rất khó khăn.

- Các tuyến du lịch: Hiện nay, mặc dù chưa có những hoạt động khai thác du lịch trekking chính thức tại VQG Xuân Sơn nhưng qua quá trình khảo sát cho thấy du khách tới đây thường tham gia vào một số tuyến du lịch bước đầu có tính chất của du lịch trekking:

+ Tuyến 1: Đi trek tuyến Núi Ten - Thác Ngọc Thác Chín Tầng. Với chiều dài khoảng $10 \mathrm{~km}$ đi bộ liên tục trong vòng $4-6$ giờ, xuất phát từ trung tâm VQG Xuân Sơn, sau đó, đi theo theo lối mòn đến suối Vàng, thác Tình Yêu độ cao chênh lệch $300 \mathrm{~m}$ - 700m. Tại đây, khách du lịch có thể tắm, bơi lội thưởng thức dòng nước trong lành và có thể cắm trại, tổ chức các hoạt động vui chơi giải trí hay qua đêm. Thời gian lưu trú trong ngày. Trong tour hầu như không có sự tham gia phục vụ của cộng đồng địa phương.

+ Tuyến 2: Đi trek tuyến hang Na - hang Lạng động Thổ Thần - bản Cỏi. Với chiều dài khoảng $15 \mathrm{~km}$, chenh lệch độ cao từ $700 \mathrm{~m}$ - 1300m, cấp độ di chuyển khó khăn hơn nhưng du khách tham gia sẽ đi qua nhiều sinh cảnh khác nhau: rừng tái sinh, nương rẫy, ruộng bậc thang, thác và suối lớn và tìm hiểu văn hóa, ẩm thực dân tộc Tày ở bản Cỏi.

Như vậy, với sự đa dạng về tài nguyên du lịch tự nhiên, cấp độ trekking tại VQG Xuân Sơn phù hợp từ mức trung bình tới mức cao nhất.

\subsection{Một số định hướng để đẩy mạnh phát triển du} lịch trekking tại vuờn quốc gia Xuân Sơn

Những định hướng phát triển du lịch trekking của VQG Xuân Sơn cần được dựa trên chiến lược phát triển du lịch Quốc gia cũng như tỉnh Phú Thọ, kế hoạch quản lý với yêu cầu bảo tồn và phát triển cộng đồng và nhu phát triển ở VQG Xuân Sơn. Những định hướng chủ yếu nhằm vào việc khai thác hợp lý lãnh thổ và tài nguyên của $V Q G$, các vùng được phân ra với mức độ sử dụng khác nhau cho du lịch trekking trên nguyên tắc ưu tiên bảo tồn và đảm bảo chất lượng du lịch, khai thác nguồn tài nguyên và quản lý du lịch thống nhất với yêu cầu bảo tồn thông qua việc tổ chức hoạt động du lịch trên các điểm, tuyến tham quan phù hợp với mức độ sử dụng của mỗi vùng trên cơ sở sức chứa, đảm bảo ủng hộ bảo tồn và hỗ trợ cộng đồng địa phương. Do đó, tác giả chú trọng vào 2 định hướng chủ yếu là:

3.3.1. Phát triển du lịch trekking theo quan điểm $d u$ lịch sinh thái

việc phát triển du lịch trekking theo quan điểm du lịch sinh thái chính là nâng cao hiệu quả hoạt động trekking về mọi mặt, đạt được sự cân bằng giữa phát triển và bảo tồn. Có nghĩa là khi đó hoạt động trekking cần phải tôn trọng và tuân thủ đầy đủ các nguyên tắc của du lịch sinh thái: Có hoạt động diễn giải nhằm nâng cao hiểu biết về môi trường, Bảo vệ, phát huy bản sắc văn hóa dân tộc, Tạo cơ hội việc làm và mang lại lợi ích cho cộng đồng địa phương.

3.3.2. Phát triển du lịch trekking gắn kết với cộng đồng địa phuơng

Đặc trưng của loại hình du lịch trekking là thực hiện tour bằng phương thức đi bộ và điểm đến là những vùng thiên nhiên hoang sơ, bản làng hẻo lánh, giao thông bất tiện nhưng chuyến đi lại không nặng nhọc, vất vả. Chính đặc điểm này đòi hỏi sự gắn kết với cộng đồng địa phương là rất quan trọng.

Du lịch trekking, tài nguyên tự nhiên và cộng đồng địa phương có quan hệ qua lại với nhau. Một tour trekking có thể không qua các thôn/làng mà chỉ nối liền các điểm đến là thắng cảnh tự nhiên với nhau, nhọng du lịch trekking muốn phát triển được lâu bền thì không 
thể thiếu được sự hỗ trợ của cộng đồng địa phơơng bởi vì tài nguyên tự nhiên với cộng đồng địa phương không thể tách rời. Mặt khác cộng đồng địa phương cần có hoạt động du lịch để cải thiện đời sống, tăng thu nhập, làm gia tăng số lượng người lao động. Nếu không hợp tác được với cộng đồng địa phương trong du lịch thì tất yếu xung đột sẽ xảy ra, ảnh hưởng tới sự phát triển du lịch.

Như vậy, du lịch trekking phát triển theo quan điểm du lịch sinh thái và gắn kết với cộng đồng là một hướng đi nhằm khai thác hiệu quả tiềm năng du lịch trekking tại VQG Xuân Sơn. Đây chính là cách giúp phát triển du lịch trekking nói riêng cũng như du lịch nói chung một cách bền vững, lâu dài.

\section{Kết luận}

Như vậy, hiện nay sự chuyển hóa các khuynh hướng nhu cầu du lịch rất đa dạng và nhanh chóng. Đặc biệt là xu hướng chuyển hóa từ du lịch thụ hưởng sang du lịch chủ động với tính tích cực vận động, tính trách nhiệm đối với môi trường và nhu cầu được trải nghiệm của du khách. Du lịch Trekking là hoạt động du lịch đi bộ khám phá, mạo hiểm đang thu hút đông đảo giới trẻ. Nó có những tác dụng tích cực đối với sự phát triển của bản thân du khách. VQG Xuân Sơn có rất nhiều tiềm năng để phát triển du lịch trekking với địa hình đa dạng, cảnh quan đẹp, điều kiện tự nhiên phong phú, tính đa dạng sinh học cao và đa dạng hệ sinh thái; hơn thế nữa các nguồn tài nguyên du lịch nhân văn của Vườn cũng vô cùng độc đáo, với 2 dân tộc thiểu số, mối dân tộc có những nét đẹp riêng trong văn hóa. Điều này tạo nên sự hấp dẫn đặc biệt đối với du khách ưa thích mạo hiểm, khám phá những điều mới lạ như khách du lịch trekking. Tiềm năng to lớn ấy cần được đánh giá và khai thác hợp lí.

\section{TÀI LIÊU THAM KHẢO}

1. Trịnh Lê Anh, "Sapa-điểm đến hấp dẫn của loại hình Trekking tour”, tạp chi Du lịch Việt Nam, số 08/2009.

2. David Noland (2001), Trekking (Outside Adventure Travels), W. W. Norton \& Company; 1 st ed edition (16 May 2001).

3. Ministry of Tourism of Oman (2012), The Oman trekking guide, Explorer Group Ltd; Illustrated edition, the $1^{\text {st }}$ edition.

4. Robert Strauss. 1996. Adventure trekking: Handbook for Independent Travelers

5. Hoàng Thị Thủy (2010), Bước đầu nghiên cưu hoạt động du lịch Trekking tại vuờn quốc gia Hoàng Liên theo quan điểm du lịch sinh thái, Khóa luận tốt nghiệp, Khoa văn hóa du lịc, Đại học dân lập Hải Phòng.

6. Ủy ban nhân dân xã Xuân Sơn (2017), Báo cáo "Đánh giá tình trạng các tuyến điểm Du lịch trên địa bàn VQG Xuân Son””.

\section{The potentials for developing trekking tour in Xuan Son national park, Phu Tho province}

\section{Do Tuyet Ngan}

\section{Article info}

\section{Recieved:}

06/4/2019

Accepted:

10/6/2019

Keywords:

Tourism;

Trekking tourism;

developing advantages;

Xuan Son national park;

Phu Tho province.

\begin{abstract}
Trekking is a type of specialized tourism has appeared in Vietnam since 1990. So far, some regions with advantages in exploiting trekking tourism have taken full advantage of that advantage to develop, such as Sapa and Lam Dong, where the type of trekking tourism is very popular for international travelers and researchers. With the attraction of natural resources, especially the diversity of topography and unique customs of ethnic minorities, Xuan Son National Park is an interesting destination for trekking, because there are basic characteristics for resource conditions for this type of tourism. Therefore, this article aims to analyze some potential to exploit the trekking tourism effectively at Xuan Son National Park.
\end{abstract}

